\title{
Formulation of Entomopathogenic Nematodes for the Control of Key Pests of Grapevine: A Review
}

\author{
A. Nxitywa, A.P. Malan* \\ Department of Conservation Ecology and Entomology, Stellenbosch University, Private Bag X1, Matieland 7602, Stellenbosch, \\ South Africa
}

Submitted for publication: January 2021

Accepted for publication: July 2021

Key words: Entomopathogenic nematodes, formulation, shelf life, infectivity

\begin{abstract}
Entomopathogenic nematodes (EPNs) are insect parasites that are used successfully as biological control agents against key pest insects of grapevine. To achieve low chemical residues and the sustainable production of grapes, it is important that biological control agents such as entomopathogenic nematodes for the control of grapevine insect pests be incorporated in an integrated pest management system for grape production. However, the commercialisation and large-scale use of EPNs is limited by their short shelf life in formulations and in storage, thus leading to poor quality and reduced efficacy against insects in the field. In South Africa, interest in the use of EPNs within an integrated pest management system has grown over the past two decades, therefore developing a formulation technique with an acceptable storage survival period, while maintaining infectivity, is essential. Moreover, the successful control of insects using EPNs is only achievable when the formulated product reaches the end user in good condition. This review is focused on the different types of formulations required for storage and ease of transport, together with the application formulation for above-ground pests and the factors affecting them. The quality assessment, storage and handling of formulated EPNs are also discussed.
\end{abstract}

\section{INTRODUCTION}

One of the major challenges in viticulture worldwide is the damage caused by insect pests. Resistant grapevine rootstocks have been developed against some insect pests, which has resulted in protection and increased crop production. However, controlling pests effectively and economically, while maintaining a sound ecological balance, remains a struggle for grape producers (Askary \& Ahmad, 2017). Most producers of wine, raisin and table grapes rely on the use of chemical pesticides, which offer a quick and easy solution in the short term, but which negatively affects the environment, soil, water and health of human beings (Vos et al., 2000). Previous research also indicates that, in most cases, biological control cannot be regarded as a once-off application for the control of grapevine insect pests. Therefore, it is of importance to develop biopesticides, like entomopathogenic nematodes (EPNs), that can be incorporated into an integrated pest management (IPM) system and that are environmentally safe and sustainable (Heriberto et al., 2017).

EPNs belonging to the families Steinernematidae and Heterorhabditidae are insect-parasitic nematodes that are used as biological control agents to control pest insects (Grewal, 2002a). The EPNs have a symbiotic relationship with pathogenic bacteria of the genera Xenorhabdus and
Photorhabdus (Poinar \& George, 1990). EPNs can be masscultured in vivo (using live insects) for small-scale use, and in vitro (liquid bioreactors) for commercial use (Ehlers et al., 1998). EPNs, in association with their bacterial symbionts, usually require between 24 and 48 h to kill their insect host (Stock, 2015).

The EPN stage that is formulated as a product, which is free-living and able to search for and infect insect pests, is called the infective juvenile (IJ) (Fig. 1). This stage, which is the only non-feeding stage in the life cycle of the nematode, is a specially adapted third larval stage and is physiologically and morphologically modified to endure adverse conditions in the soil environment. IJs penetrate the insect through natural openings (the mouth, the spiracle or the anus), or through thin sections of the cuticle, and release the bacterial symbiont into the haemocoel (Banu et al., 2017). Once inside the insect, both the bacteria and the nematode release toxins that lead to the rapid death of the insect (Lu et al., 2017). The bacteria reproduce exponentially and the activated nematodes start feeding on the host tissue, which enables them to grow into adults and to reproduce. As soon as the supply of food in the insect cadaver is depleted, a new cohort of IJs leaves the dead insect in search of a new host (Han \& Ehlers, 2000; Ehlers, 2001; Han \& Ehlers, 2001). Although

*Corresponding author: apm@sun.ac.za

Acknowledgements: The authors wish to thank the Department of Conservation Ecology and Entomology, Stellenbosch University, for funding the project; and Dr Mia Cloete, for proofreading the manuscript 


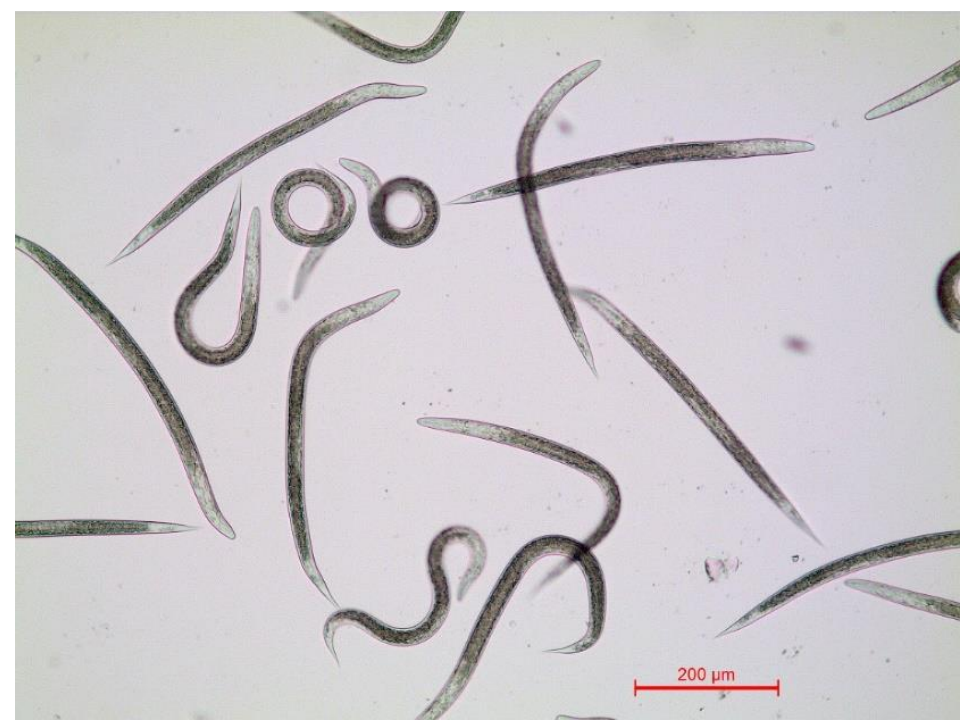

FIGURE 1

The infective juvenile stage of entomopathogenic nematodes to be formulated for application against grapevine pest insects.

they are highly lethal against many different insect pests, they are regarded as environmentally safe, posing no health risk to either humans or vertebrate animals. Therefore, no specialised protection, like masks, safety boots and gloves, is required during their application (Shapiro-Ilan \& Gaugler, 2002).

Although EPNs have proven to be successful biocontrol agents of insects, their efficacy under large-scale production is impaired by their short shelf life, which is due to their need to maintain biological activity, their high oxygen demand and their sensitivity to extreme temperatures. The development of a successful formulation with an acceptable survival time for EPNs to be able to fulfil their role as effective biocontrol agents is of importance. Both logistical and practical factors, such as transport time and the application window from when farmers receive the product and the correct time to apply, require consideration. IJs depend mainly on their stored reserves for survival (Silver et al., 1995 Grewal \& Peters, 2005). During mass production and formulation, the quality and quantity of the stored reserves - especially lipids, which constitute between $32 \%$ and $43 \%$ of the total body mass - and the utilisation rate during storage, correlate with the shelf life of the IJs (Selvan et al., 1993; Grewal \& Peters, 2005).

Ehlers (2007) suggests that, for an EPN formulation to be a successful product, it should be formulated soon after nematode production so as to limit the formulation of dead nematodes, which might compromise the storage process. To improve the large-scale use of EPNs as biological control agents, ongoing research focuses on the development of IJ formulations that are cost-effective, that can survive storage at room temperature for relatively long periods, that can be transported and applied easily, and that have high infectivity against host insects (Shapiro-Ilan et al., 2012; Grzywacz et al., 2014; Ruiz-Vega et al., 2018).

In South Africa, the use of exotic EPN species is prohibited by the regulations of the Amendment to the Agricultural Pest Act, No. 36 of 1974, which forbids the importation of exotic insect or animal species (Government Gazette of the Republic of South Africa, 1989). In the light of the above, additional research is being focused on using local EPN isolates to control insect pests in South African agricultural industries, and many successful laboratory and vineyard experiments have already been carried out (Malan \& Hatting, 2015; Hatting \& Malan, 2017; Malan \& Ferreira, 2017). With the success in in vitro liquid mass culture, these nematodes can be cultured in high numbers (Dunn et al., 2020a, 2020b) and formulated successfully (Kagimu \& Malan, 2019). For example, Steinernema yirgalemense Nguyen, Tesfamariam, Gozel, Gaugler \& Adams was shown to be highly effective against the vine mealybug, grapevine leaf miner and the banded fruit weevil in laboratory trials (Le Vieux \& Malan, 2013; Steyn et al., 2019a; Dlamini et al., 2020). Both in vivo- (Le Vieux \& Malan, 2013) and in vitrocultured nematodes (Steyn et al., 2019b) have proven to be effective in laboratory trials and field trials for potentially controlling pests of grapevine.

EPNs were first mentioned in South Africa in the early $1950 \mathrm{~s}$, when they were isolated from all the life stages of the black maize beetle, found in a maize field in the Eastern Cape province near Grahamstown (Harington, 1953). However, attempts to use these organisms for pest control only started in the late 1980s, when they were applied above ground against sugarcane borer by researchers at the South African Sugar Association Experimental Station (Spaull, 1988).

To date, there have been no reports of any locally available EPN products on the South African market, unlike in European countries and the United States of America, although emergency registration was obtained for Heterorhabditis bacteriophora Poinar, imported from e-nema Germany (Hatting et al., 2019). Heterorhabditis bacteriophora is one of the most common EPN species in 
citrus orchards (Malan et al., 2011). The commercial use of EPNs in South Africa is still in its infancy, as additional research on the mass production and formulation of local species is still under way. Recently, successes achieved with in vitro culture have been reported by Ferreira et al. (2015) and Dunn et al. (2020a), while Kagimu and Malan (2019) have reported success with a formulation using diatomaceous earth and the encapsulation of EPNs within alginate calcium. Ramakuwela et al. (2015) successfully cultured a local species, Steinernema innovationi Çimen, Lee, Hatting, Hazir $\&$ Stock in vitro, using an artificial medium on sponge. The nematodes were stored on a sponge formulation at $15^{\circ} \mathrm{C}$ with a $91 \%$ survival rate after 84 days and $100 \%$ infectivity against Galleria mellonella (Lepidoptera: Pyralidae).

Many attempts to make a viable nematode product have failed. To ensure success, developing a formulation technique with a long storage period, low or no mortality over time and a high infectivity rate is crucial (Strauch et al., 2000; Hussein \& Abdel-Aty, 2012). In spite of the limitations pertaining to the survival of EPNs in formulations, improving the formulation technique is likely to increase the EPN survival rate and to improve application (Perry et al., 2012). This is evident from the numerous formulated products selling commercially (Table 1$)$.

The current review explores the different types of formulation methods investigated previously. The focus is on formulation for storage and transport, as well as formulation for application (for aboveground pests) for potential largescale commercial application of EPNs in our local industries, like grapevine, citrus and deciduous fruit.

\section{THE NATURE OF EPN FORMULATION}

Formulation is the development of a product by mixing the active ingredient with non-active ingredients, possibly including organic products. In the case of EPN formulations, the IJs are the active ingredient. The formulated product typically includes non-active ingredients, such as absorbents, adsorbents, antimicrobial agents, antioxidants, binders, carriers, dispersants, preservatives, solvents, surfactants and UV absorbers (Grewal, 2002a).

The main difference between an EPN formulation and other chemical pesticide formulations lies in the need to maintain biological activity during storage and application (Georgis, 1990). The type of formulation to be used, and its ingredients, depend on understanding the physiological chemistry, the ecology and the behaviour of the nematode species (Georgis \& Kaya, 1998).

\section{REASONS FOR FORMULATION}

The large-scale use of mass-produced nematodes for commercial application requires storage of the product, transport to the field, ease of application in the field, and good-quality nematodes. Therefore, nematodes are formulated for convenient storage ability and improved shelf life. According to Grewal (2002a), there have been no reports of nematodes in formulation that are comparable to chemical pesticides in terms of cost and shelf life, with nematodes being more expensive to produce due to the high production costs involved, and due to them having a relatively short shelf life.
EPNs are usually stored in water suspensions in culture flasks at temperatures ranging from $4^{\circ} \mathrm{C}$ to $15^{\circ} \mathrm{C}$ in which, depending on the species used, they can survive for a period of three to 12 months (Chen \& Glazer, 2005). Although mass-produced nematodes can also be stored in suspension for weeks in large refrigerated bubble tanks, such a storage method poses a high risk of contamination and sets a high demand for oxygen (Bečvář \& Mráček, 2000). For the abovementioned reasons, it can be concluded that the formulation of EPNs is done largely for the sake of convenience and quality conservation.

\section{FORMULATIONS FOR STORAGE AND TRANSPORT}

Nematodes for long-term storage and transportation to the field can be formulated using different techniques. The formulation should be done while the nematodes are fully active and either moving, or slightly desiccated, so as to reduce their mobility (Grewal, 2002a). As EPNs are live, multicellular organisms, their quality tends to decline over time, regardless of the formulation type used, due to declining reserves. This is because the EPNs consume their lipid reserves over time (Lewis \& Perez, 2004). According to Grewal and Peters (2005), there are two main distinctive approaches to formulations that make them suitable for storage and transportation. One is the use of inert carriers, such as sponge and vermiculite, which allow for sufficient gaseous exchange, while the other is the induction of a state of partial anhydrobiosis, which is attained by reducing the metabolic state and activity of the nematodes, resulting in the conservation of their energy resources.

\section{Actively moving nematodes}

For the storage and transportation of nematodes in small quantities, sponge and vermiculite-based formulations are used. However, such formulations, especially sponge, are not suitable for high nematode densities. Due to the mobility of IJs in such formulations, they are at high risk of escaping from the substrate, which tends to lead to the depletion of energy reserves and to possible desiccation (Grewal, 2000a; Grewal \& Peters, 2005). Although they are inexpensive to apply, their need for continuous refrigeration during storage and transportation is also expensive (Grewal, 2000a).

\section{Reduced mobility}

Nematodes lose energy during movement, therefore the goal of formulation is to minimise the activity of the IJs for the preservation of their stored energy reserves. This is achieved in some formulations by the slight desiccation of IJs through the addition of ingredients that are capable of reducing water activity, thereby causing partial anhydrobiosis, which is referred to as 'quiescent anhydrobiosis' (Bedding, 1988; Silver, 1999; Grewal, 2000b, 2000c). Such a state mimics the IJ's natural state in the soil. During extreme soil dehydration, EPNs undergo a state of partial cryptobiotic anhydrobiosis, during which they enter a reversible inactive state, which is typically noticeable in the summer rainfall regions (Crowe \& Crowe, 1992). During the desiccated state in the soil, some plant-parasitic nematodes of the family Heteroderidae have the ability to survive for up to 30 years (Wharton, 1986; Womersley et al., 1998). Unfortunately, EPNs cannot tolerate 
TABLE 1

The most recent examples of different types of Steinernema and Heterorhabditis species formulations, with a survival rate of above $60 \%$ during their storage period (shelf life) given in weeks (w) or months $(\mathrm{m})$.

\begin{tabular}{|c|c|c|c|c|c|}
\hline Formulation & $\begin{array}{l}\text { Nematode } \\
\text { species }\end{array}$ & Shelf life & $\begin{array}{c}\text { Temperature } \\
\left({ }^{\circ} \mathrm{C}\right)\end{array}$ & $\begin{array}{c}\text { Survival } \\
\% \\
\end{array}$ & References \\
\hline \multicolumn{6}{|l|}{ Actively moving: } \\
\hline \multirow[t]{2}{*}{ Sponge } & S. innovationi & $12 \mathrm{w}$ & 15 & 86 & Ramakuwela et al. (2015) \\
\hline & S. carpocapsae & $13 \mathrm{w}$ & 16 & 89 & Andalo et al. (2011) \\
\hline \multirow[t]{4}{*}{ Vermiculite } & S. feltiae & $34 ; 33 ; 4 \mathrm{w}$ & $15 ; 25 ; 35$ & $>80$ & Leite et al. (2018) \\
\hline & S. feltiae & $17 \mathrm{w}$ & 5 & $>90$ & Guo et al. (2017) \\
\hline & S. carpocapsae & $17 \mathrm{w}$ & 5 & $>90$ & Guo et al. (2017) \\
\hline & S. longicaudatum & $17 \mathrm{w}$ & 5 & $>90$ & Guo et al. (2017) \\
\hline \multirow[t]{4}{*}{ Liquid concentrate } & H. bacteriophora & $33 \mathrm{w}$ & 27 & 89 & Strauch et al. (2000) \\
\hline & H. indica & $6 \mathrm{w}$ & 25 & 60 & Strauch et al. (2000) \\
\hline & Steinernema sp. & $6-10 \mathrm{~m}$ & 5 & - & Hazir et al. (2003) \\
\hline & Heterorhabditis & $0-3 \mathrm{~m}$ & 5 & - & Hazir et al. (2003) \\
\hline \multirow[t]{3}{*}{ Flowable gels } & S. abbassi & $4 \mathrm{w}$ & 25 & 69 & Ganguly et al. (2008) \\
\hline & S. carpocapsae & $4 w$ & 25 & 67 & Hussein \& Abdel-Aty (2012) \\
\hline & S. carpocapsae & $3-4 \mathrm{~m}$ & 25 & - & Grewal (2002a) \\
\hline \multicolumn{6}{|l|}{ Reduced mobility: } \\
\hline \multirow[t]{3}{*}{ Wettable powders } & H. bacteriophora & $24 \mathrm{w}$ & 23 & 99 & Kagimu et al. (2017) \\
\hline & S. jeffreyense & $4 \mathrm{w}$ & 25 & 65 & Kagimu et al. (2017) \\
\hline & H. megidis & $2-3 \mathrm{~m}$ & 25 & - & Grewal (2000a) \\
\hline Water-dispensable granules & S. glaseri & $1 \mathrm{w}$ & 25 & - & Cortés-Martínez et al. (2016) \\
\hline \multirow[t]{2}{*}{ Alginate beads } & S. feltiae & $24 \mathrm{w}$ & 23 & 99 & Chen and Glazer (2005) \\
\hline & S. carpocapsae & $4 \mathrm{w}$ & 25 & 65 & Hussein and Abdel-Aty (2012) \\
\hline
\end{tabular}

total dehydration and, for that reason, the use of partial anhydrobiosis is a critical step in their survival. Nematodes in an anhydrobiotic state have the ability to better withstand both warm and cold temperatures than in a more active state (Glazer \& Salame, 2000; Grewal \& Jagdale, 2002). Ongoing research is focused on the development of an IJ formulation type that can be stored at high concentrations for relatively long periods of time, while maintaining its effectiveness against the target host, along with heightened field persistence (Grewal, 2002a; Shapiro-Ilan et al., 2012). Formulations with the abovementioned characteristics of partial anhydrobiosis include powders, granules and alginate beads (Grewal, 2000a).

\section{Sponge}

Polyether-polyurethane sponge sheets, or cubes, can be used as carriers for nematode formulations (Grewal \& Peters, 2005). Nematode density differs according to the size of the nematodes involved. The use of sponge as a carrier can mimic the natural environment by providing the IJs with a large surface area for the desired oxygen exchange through the sponge perforation (San-Blas, 2013).

Multiple studies to assess the longevity and infectivity of nematodes on artificial sponge formulations have shown that success can be achieved (Bedding, 1984; Strauch et al., 2000; Ley \& Mundo-Campos, 2004; San-Blas, 2013; Ramakuwela et al., 2015). During an experiment conducted by Andalo et al. (2011), the survival rate of Steinernema carpocapsae (Weiser, 1955) Wouts, Mráček, Gerdin \& Bedding in sponge formulation at $16^{\circ} \mathrm{C}$ was found to be $89.3 \%$ after 90 days and $57.5 \%$ after 180 days. However, for large-scale application, the required high-concentration formulation would not be attainable, and the amount of sponge used would not be environmentally acceptable. Completely separating the nematodes from the sponge is also very difficult.

\section{Vermiculite and peat}

A formulation of vermiculite and peat can be seen as an improvement on the sponge formulation, as it has the advantage of using much higher IJ densities with prolonged storage shelf life. However, this type of formulation poses problems in application, as it should be broadcasted or 
applied in a mulch. Conventional spraying is difficult because, even with the spray nozzle removed to avoid clogging, vermiculite and peat particles tend to be too large to fit through the nozzle head.

Leite et al. (2018) recently formulated Steinernema feltiae (Filipjev, 1934) Wouts, Mráček, Gerdin \& Bedding, using a mixture of vermiculite and polyacrylamide gel stored at three different temperatures, viz. $15^{\circ} \mathrm{C}, 25^{\circ} \mathrm{C}$ and $35^{\circ} \mathrm{C}$, which had previously not been attempted. The survival of $S$. feltiae in the combination was reported to be higher than $80 \%$ for 241 days ( 34 weeks) at $15^{\circ} \mathrm{C}$, for 233 days ( \pm 33 weeks) at $25^{\circ} \mathrm{C}$, and for 30 days at $35^{\circ} \mathrm{C}$. Another formulation study by Guo et al. (2017) reported a survival rate of more than $90 \%$ after 120 days at a storage temperature of $5^{\circ} \mathrm{C}$ for $S$. carpocapsae, S. feltiae and Steinernema longicaudum Shen $\&$ Wang when formulated in a mixture of vermiculite and humus.

\section{Mineral oxygenated water}

Entomopathogenic nematodes stored in water in oxygenated refrigerated tanks can last for several months. The survival period of Steinernema tends to be between six and 12 months, and that of Heterorhabditis from three to six months (Hazir et al., 2003). The storage method is currently employed in large-scale and commercial use, with formulation on demand. Many factors contribute to the unsuitability of EPNs stored in mineral oxygenated water, such as their need for high oxygen levels and the sensitivity of some nematode species to very low or high temperatures. The required species' optimum survival temperatures need to be regulated constantly to suit the species being stored (Shapiro-Ilan \& Gaugler, 2002; Grewal \& Peters, 2005).

\section{Flowable gels}

Gel formulations made from polyacrylamide were developed for nematode storage by Bedding and Butler (1994), in terms of which the EPNs were partially desiccated. The formulations showed low survival rates at room temperature. During this time, Chang and Gehret (1992) developed a formulation using sodium alginate. Subsequently, Chen and Glazer (2005) improved the formulation type by encapsulating the $S$. feltiae within alginate capsules. Gel formulations, which are among the formulations requiring direct field application, are suitable for room temperature storage. This has been proven by Grewal (2002a) in terms of an alginate gel formulation of $S$. carpocapsae, which managed to last as long as three to four months when stored at room temperature $\left(25^{\circ} \mathrm{C}\right)$. In another study, nematodes were mixed with a flowable gel to make a NemaGel type of formulation. The formulation was compared to alginate formulation at room temperature, with it being found that the longevity was reduced (Georgis, 1990). In contrast with the findings of Georgis (1990), Ganguly et al. (2008) report that the IJs of Steinernema abbassi Elawad, Ahamad \& Reid (syn. S. thermophilum) in NemaGel formulation lasted for a period of nine months, with an $89 \%$ survival rate, despite the temperature fluctuations ranging between $15^{\circ} \mathrm{C}$ and $39^{\circ} \mathrm{C}$.

\section{Wettable powder}

The first use of a powder formulation was reported in the 1980 s, consisting of clay mixed with the nematodes to remove excess water and induce partial anhydrobiosis (Bedding, 1988). The formulation became known as a 'sandwich', as the nematodes were layered between the clay layers. Biotechnology Australia Ltd. commercialised the product but, due to its poor storage ability and clogging of the spraying equipment, it was discontinued. However, the formulation was later improved with the development of wettable powder formulations, with suitable room temperature storage conditions being established for both the steinernematids and the heterorhabditis (Grewal, 1998).

A powder formulation is easy to work with and to apply due to its ability to dissolve in water. Recently, the most common powder used in the formulation of EPNs has been diatomaceous earth (DE). DE is a naturally occurring sedimentary rock, consisting of a fine white powder of varying particle sizes. It is used in the agricultural industry as an insecticide due to its desiccation ability. Recently, Kagimu et al. (2017) reported the advantages of using DE in formulations, including ease of application. When diluted, applications can be administered during irrigation, using the already available farm irrigation systems with no need for specialised equipment. Kagimu and Malan (2019) regard $\mathrm{DE}$ formulations as having great potential for formulation technology due to their ability for optimisation. In their study, in which three South African species (S. yirgalemense, Steinernema jeffreyense Malan, Knoetze \& Tiedt and $H$. bacteriophora) were formulated using DE, the survival and infectivity rates were still high, even in the fourth week, at storage temperatures of both $14^{\circ} \mathrm{C}$ and $25^{\circ} \mathrm{C}$.

\section{Water-dispersible granules}

The method of EPN formulation in granules or pellets was first described by Capinera and Hibbard (1987). The researchers used lucerne meal and wheat flour to encase the nematodes, inducing partial anhydrobiosis. An improved water-dispersible granular (WG) formulation was later developed, in which the IJs were encapsulated in various mixtures of powders (silica, clays, starches, lignin and cellulose) (Georgis et al., 1995; Silver et al., 1995). Current research focuses on the development of EPN formulations with a prolonged shelf life, enhanced storage ability, high effectivity against the targeted organisms, and increased field persistence (Grewal, 2002a; Shapiro-Ilan et al., 2012). Granular formulations meeting the abovementioned requirements (Grewal, 2000a) were developed specifically to upscale the IJ density in formulations and to overcome the issue of short-term storage during transportation (Georgis \& Dunlop, 1994).

Moisture content is among the factors that influence the shelf life and anhydrobiosis of formulated EPNs (Grewal, 2002a; Bazardeh \& Esmaiili, 2014). On investigating the effect of moisture evaporation on Steinernema glaseri Wouts, Mráček, Gerdin \& Bedding pellets, Cortés-Martínez et al. (2016) concluded that, for S. glaseri pellets to have increased storage stability, the moisture level must be retained at $27 \%$. Steinernema carpocapsae, used in a granular formulation experiment conducted by Grewal (2002a), was found to have 
a shelf life of seven months at $25^{\circ} \mathrm{C}$. The study indicated the positive correlation between the induction of anhydrobiosis and the longevity of IJs.

Ellenby (1968) and Wharton (2002) suggest that the main factor contributing to the survival of desiccated anhydrobiotic nematodes is the controlled rate of body water loss. Different species adapt to anhydrobiosis in a variety of ways: the survival ability of $S$. carpocapsae is enhanced by a fast rate of water loss, whereas $S$. glaseri survives well with a low rate of water loss (Patel et al., 1997a; Nimkingrat et al., 2013). Recently, Cortés-Martínez et al. (2017) reported the importance of pre-acclimatisation on $S$. glaseri when producing pellets to prolong survival time. Steinernema glaseri that were pelletised in $\mathrm{DE}$ and stored at $23 \pm 3^{\circ} \mathrm{C}$ had a longer survival period and a higher rate of infectivity against Phyllophaga vetula Horn (Coleoptera: Sarabaeidae) when they were pre-acclimatised, as compared to when they were applied in non-pre-acclimatised pellet formulations (Cortés-Martínez et al., 2017).

\section{Alginate beads and capsules}

The entrapment of IJs in alginate beads was developed to improve the shelf life of nematodes, and as an ultraviolet (UV) light and desiccation protectant (Navon et al., 2002; Kagimu \& Malan, 2019). Beads and capsules are easy to handle and package (Patel \& Vorlop, 1994). A recent review by Vemmer and Patel (2013) explains how such beads, or capsules, are formed. Basically, formation occurs through the process of gelation or membrane formation in the beads.

The first attempt at EPN encapsulation was made by Kaya and Nelsen (1985), whereby the alginate EPN solution was dropped into the $\mathrm{CaCl}_{2}$ solution, resulting in the immediate formation of capsules of about $1.5 \mathrm{~mm}$ diameter, with the nematodes being immobilised on the inside of the solid core. However, the nematodes reportedly can escape from the beads when they are too soft (Hiltpold et al., 2012; Kim et al., 2015). In an experiment by Kim et al. (2015), the IJs escaped from the soft beads within a few days, especially when the formulation was not refrigerated. The capsule properties were adjusted, with a higher concentrations of $\mathrm{Ca}^{2+}$ and with reactions being performed at $4{ }^{\circ} \mathrm{C}$, which resulted in hard capsules that were relatively thinly shelled. Although the hard capsules managed to retain the IJs better than the soft ones, a major concern was that the IJs ultimately were unable to escape from the beads. Ideally, the viability of the IJs should be maintained for a couple of months, with the EPNs entrapped inside the capsule or bead until required for use (Kim et al., 2015). Similarly, Hiltpold et al. (2012) reported that the IJs escaped from the soft capsules a few days after formulation, which proved that the capsule properties needed adjustment to improve the entrapment and to achieve extended shelf life for the EPNs. Kagimu and Malan (2019) also reported an increase in the number of IJs escaping from the beads as the storage temperature increased.

\section{Application formulation \\ Infected insect cadavers}

The use of infected insect cadavers is an alternative method of applying EPNs in glasshouses and in fields for small-scale to medium-sized growers (Del Valle et al., 2008; Monteiro et al., 2014). The production cost of cadaver formulation is lower, but more labour-intensive compared to other formulations. The disadvantage of using this formulation method is the breaking and rupturing of the insect cadaver during storage, transport and shipping. However, coating the insect cadaver with a protective formulation, like starch or clay, can overcome this limitation (Shapiro-Ilan et al., 2001). No specialised equipment is required for the application of insect cadavers, as producers can just broadcast them in the glasshouse or field (Monteiro et al., 2014). In this method, the larvae are inoculated with IJs and, after a few days, the infected cadavers are released in the field, where the IJs will complete their life cycle. A new cohort of IJs will then leave the cadaver in search of a new host, thereby acting to control the target pest (Shapiro-Ilan et al., 2001).

The most commonly used larvae are those of wax moths, Galleria mellonella (Del Valle et al., 2008), because they are highly susceptible and have high IJ-production and quality value (Shapiro-Ilan et al., 2001). Van Zyl and Malan (2015) indicate that, by using wax moth larvae, a mean number of 1459205 and 1898512 IJs can be produced per gram of host. However, Costa et al. (2007) claim that the use of $G$. mellonella is expensive due to their costly diet. Another alternative is the use of mealworms, Tenebrio molitor L. (Coleoptera: Tenebrionidae) (Batista \& Auad, 2010; Shapiro-Ilan et al. 2010), whose diet can be much more cost-effective than the above. However, in comparison with $G$. mellonella, T. molitor tends to produce significantly fewer IJs (Shapiro-Ilan et al., 2002; Van Zyl \& Malan, 2015). Insect cadaver formulations have been reported to be successful in the laboratory, as well as in greenhouses and under field conditions (Del Valle et al., 2008; Ansari et al., 2009). The method has also been used effectively to control Rhipicephalus microplus (Canestrini) (Ixodida: Ixodidae), the Brazilian cattle tick (Monteiro et al., 2014).

\section{Bait stations}

Bait formulations are mainly made of the following ingredients: IJs, a mixture of inert carriers, a feeding stimulant, sex pheromones and a toxicant (Georgis \& Kaya, 1998; Grewal, 2002a). In those situations where irrigation is impractical, bait formulations can be used for the control of insect pests. In a study conducted by Capinera and Hibbard (1987), two S. feltiae baits were prepared to be tested against grasshoppers. One bait formulation consisted of calcium alginate capsules with 5\% wheat bran, while the second bait was an alfalfa-wheat pellet bait, consisting of alfalfa meal, wheat flour, wheat bran, corn oil and locust bean gum $(0.5 \%)$. The results showed the suppression of locusts within two days of application. Both the bait formulations had a positive effect on the percentage of grasshopper mortality compared with the control treatments. Bait formulations were also evaluated in laboratory experiments on cutworms and tawny mole crickets (Georgis, 1990). In the experiment, hydroxyethyl cellulose and glycerine were added to minimise the migration of IJs from the bait. No significant differences were found between bait formulations and an aqueous suspension of IJs used against black cutworms under field conditions, although the former did outperform the controls.

No recent reports of studies using bait formulations of 
EPNs were found. A bait station of gel on a riffled plank was developed by e-nema for the control of the black vine weevil. In the formulation, IJs of $S$. carpocapsae, mixed with gel are pressed into furrows in wood. The IJs are reported to have a shelf life of at least six weeks. For application, the board is placed upside down, with irrigation being recommended when the soil is dry (https://www.e-nema.de/professionalen/tree-nurseries/).

\section{Above-ground application}

A number of studies have reported the successful use of EPNs against above-ground pests. However, IJs are sensitive to UV rays and are prone to desiccation when they are exposed to sunlight or applied in dry environments, as is evident in a recent review by Platt et al. (2020). The addition of adjuvants, surfactants (e.g. oil) or humectants (e.g. gels) can prolong their persistence in the soil, thereby enabling them to be more effective than they would have been (Portman et al., 2016). An experiment by Noosidum et al. (2016) showed that the addition of $0.25 \%$ and $0.5 \%$ humectant (Barricade) to $S$. feltiae spray formulations improved efficacy against the larvae of Spodoptera litura F.(Lepidoptera: Noctuidae), with a mortality of $66.0 \%$ and $61.5 \%$, respectively. A humectant, which is a good source of moisture for EPNs, serves as a protectant from sunlight (Dito et al., 2016).

\begin{abstract}
Adjuvants
The addition of adjuvants to formulations is reported to enhance the survival rate of IJs, as they aid in the suppression of microorganism growth, thereby acting as an antimicrobial and antifungal agent. The most commonly used adjuvants are organic acids, with such substances being used in the food industry as food preservatives and, being safe for the environment, also for humans and other higher organisms (Strauch et al., 2000). Of the organic acids (ascorbic acid, citric acid, benzoic acid and sorbic acid) that were added as adjuvants to liquid $H$. indica IJ formulations made of phosphate buffer, only ascorbic acid improved the survival of the IJs. When dried spices (cinnamon, cloves, rosemary and oregano) were used in a liquid formulation made of Ringer's solution, only the cinnamon and cloves were found to improve the survival of the IJs (Strauch et al., 2000). Studies have also shown the adjuvants to improve the efficacy of EPNs. For example, when S. yirgalemense suspensions were mixed with adjuvants $\left(\mathrm{Zeba}^{\circledR}\right.$ and $\left.\mathrm{Nu}-\mathrm{Film}^{\circledR}\right)$ and applied against Planococcus ficus (vine mealybug), the extent of control achieved was found to be greater than when no adjuvants were added, with a mortality rate of $84 \%$ under laboratory conditions and $88 \%$ in glasshouse trials, while the mortality rate obtained by the control (water only) was $28 \%$ and $30 \%$, respectively (Platt et al., 2018).
\end{abstract}

\section{Oil emulsions}

When EPNs are formulated in water, evaporation can lead to the formulation drying out and to the nematodes desiccating. The use of oil in formulations can delay the desiccation rate of EPNs, leading to an improved interaction with the targeted insect. Oil has a much lower evaporation rate than water due to its higher viscosity (Aquino-Bolaños et al., 2019a). When Aquino-Bolaños et al. (2019b) experimented with different oil suspensions (Cymbopogon citratus, Pelargonium sp., Juniperus virginiana, Rosa sp. and Mentha piperita) in EPN (H. bacteriophora, S. carpocapsae and Steinernema websteri) formulations against adult ticks, a combination of $33 \% \mathrm{~J}$. virginiana oil with $S$. websteri resulted in $80 \%$ to $100 \%$ control effectiveness $24 \mathrm{~h}$ post-application.

\section{FACTORS AFFECTING THE SURVIVAL OF FORMU- LATED EPN}

For the successful commercialisation of nematodes, it is important to develop a formulation that is able to maintain a relatively long shelf life of more than three to four months. Understanding the underlying factors influencing the quality of the formulated EPNs is crucial for being able to manipulate the formulation techniques for the improved survival and longevity of EPNs, as well as for ease of transport and application. Different factors affecting the formulation of IJ have been investigated.

\section{Energy reserves}

Infective juveniles consist of approximately $60 \%$ lipids, which they use as their main energy reserves (Selvan et al., 1993). EPN species differ with respect to the extent of their available reserves (Grewal \& Georgis, 1998). In the case of steinernematids, there generally are more lipids present than in heterorhabditids (Womersley, 1990). The amount of stored lipids in the IJ has been shown to be determined by the type of artificial medium used during the culturing process (Grewal, 2000c). IJs, which are the non-feeding stages of the EPN, depend mainly on their stored reserves for survival and infectivity, with studies having indicated a direct proportionality between the amount of energy reserves present and the rate of infectivity achieved (Patel \& Wright, 1997a, 1997b, 1997c; Patel et al., 1997a, 1997b).

\section{Desiccation}

During anhydrobiosis, nematodes tend to lose a substantial amount of water. This state in EPNs is reversible up to a critical point, which is why the process is known as 'partial' anhydrobiosis. Anhydrobiosis, through slight desiccation, is reported as a method used to improve the longevity of stored nematodes (Barrett, 1991). Obtaining long storage periods through desiccation enables the slowing down of the metabolism. The above was confirmed by an experiment conducted by Grewal (2000b), who compared the shelf life of desiccated nematodes with that of non-desiccated ones stored at low temperature.

\section{Microbial contamination}

The formulated product must be free of any microbial contamination, as contamination tends to affect the quality negatively, to degrade the value of the product, and to lead to low efficacy. Formulations with a high moisture content are prone to microbial contamination (Grewal, 2002a). Microbial contamination, especially by fungi, can decrease the amount of available oxygen and, by competing with the nematodes, lead to nematode death. Contamination can also be a problem during application, as dead particles and contaminants can clog spray nozzles. The most commonly reported microbial contaminants include bacterial species, 
yeast and fungi (Grewal, 1998). Although antimicrobial and antifungal agents can be used to delay the growth of microbes, they must be used with caution, as they can also affect the survival rate of nematodes. Moreover, different nematode species exhibit different degrees of sensitivity to antimicrobial agents. Steinernema feltiae and $S$. riobrave Cabanillas, Poinar \& Raulston were found to show increased sensitivity to a commonly used antimicrobial agent, Proxel $^{\mathrm{TM}}$ (Grewal, 2002a). Furthermore, the moisture content of the formulation has a drastic effect on the development of microbial agents, as has been shown in investigations of water activity in relation to the longevity and quality of formulated EPNs. Kagimu (2018) reported a decrease in the survival rate of $S$. yirgalemense due to bacterial contamination and toxin production at high values of water activity.

\section{Temperature during storage and handling}

Studies have shown a variation between different EPN species regarding survival and infectivity at different temperatures. Recently, Kagimu and Malan (2019) conducted a study on the formulation of three South African species, S. yirgalemense, $S$. jeffreyense and $H$. bacteriophora. Using diatomaceous earth and alginate calcium as formulation media, they tested the survival of EPNs at $6^{\circ} \mathrm{C}, 14^{\circ} \mathrm{C}$ and $25^{\circ} \mathrm{C}$. The results indicate that storage at $6^{\circ} \mathrm{C}$ was significantly different in terms of survival and infectivity compared to storage at $14^{\circ} \mathrm{C}$ and $25^{\circ} \mathrm{C}$ in both formulations, with a drastic decline, in terms of the $S$. yirgalemense, over time. All three EPN species showed a poor survival rate and decreased infectivity at low temperatures.

Another South Africa-based study, by Ramakuwela et al. (2015) on the survival and infectivity of the local EPN species S. innovationi Çimen, Lee, Hatting, Hazir \& Stock, was undertaken at five different storage temperatures $\left(5^{\circ} \mathrm{C}, 10^{\circ} \mathrm{C}, 15^{\circ} \mathrm{C}, 20^{\circ} \mathrm{C}\right.$ and $\left.25^{\circ} \mathrm{C}\right)$. The EPNs were stored in an aqueous suspension with $0.1 \%$ formalin. The results achieved at $5^{\circ} \mathrm{C}$ were found to be significantly better when compared to the results at other temperatures, with a survival percentage of $35 \%, 17 \%$ and $13 \%$ recorded on days 28,52 and 84 , respectively. However, the IJ survival rate recorded at $15^{\circ} \mathrm{C}$ was the highest. There were no significant differences in the survival rates at storage temperatures of $20^{\circ} \mathrm{C}$ and $25^{\circ} \mathrm{C}$. A study conducted by Strauch et al. (2000) also found that the prevailing temperature affects the survival of EPNs. Heterorhabditis bacteriophora and Heterorhabditis indica Poinar, Karunakar \& David were stored in Ringer's solution at different temperatures, ranging from $5^{\circ} \mathrm{C}$ to $25^{\circ} \mathrm{C}$. In $H$. bacteriophora, the best survival temperature was found to be $7.5^{\circ} \mathrm{C}$, with a survival percentage of $>70 \%$ on day 125 , while a drastic decrease was seen from 25 days of storage at $25^{\circ} \mathrm{C}$, with $100 \%$ mortality on day 50 . Heterorhabditis indica survived the best at $15^{\circ} \mathrm{C}$, with a survival rate of at least $>40 \%$ on day 85 ; while stored at $5^{\circ} \mathrm{C}$, its mortality was found to be $100 \%$ on day 25 . The abovementioned studies all confirm that storage temperature is important for the survival EPNs.

Previous studies indicate the cost implications of storing formulations at low temperatures, as refrigeration can be expensive, thus increasing the cost of the formulated EPN product (Westerman, 1992; Strauch et al., 2000; Goud et al., 2010). A study conducted by Ramakuwela et al. (2015) indicated that the costs of EPNs can be reduced if the temperature of the IJs can be raised from refrigerator temperature to room temperature during purchase and application. The results obtained with $S$. innovationi showed that the rate of infectivity against $G$. mellonella still exceeded $90 \%$ after being stored at $15^{\circ} \mathrm{C}$ for 84 days and then at room temperature for two weeks.

Differences in temperature tolerance for storage between EPN species are affected by the origin of the nematode species, as it has been found that species isolated from relatively warm areas tend to have a lower cold tolerance compared to those that have been isolated from cold localities, which have a lower tolerance for warmer temperatures (Grewal, 2002a). Formulation type can also affect the nematode response to temperatures. This was evident in a study conducted by Grewal (2000b), in which the shelf life and infectivity of $S$. carpocapsae in a wettable granule (WG) formulation were compared to $S$. carpocapsae kept in liquid storage at $25^{\circ} \mathrm{C}$. The survival stability of the WG formulation lasted up to seven months, whereas that of the liquid-stored nematodes lasted only up to four months. Although the infectivity against $G$. mellonella did not differ significantly between the IJs that were kept in WG formulation and those that were kept in water for the first three months of the experiment, both ultimately resulted in mortality of greater than $70 \%$.

Formulations with induced partial anhydrobiosis tend to have a relatively longer shelf life due to their lowered metabolic rate and reserved energy. Nematodes with induced anhydrobiosis through desiccation, rather than non-desiccated ones, can withstand temperature extremes, therefore offering enhanced stability during handling and transportation (Grewal, 2002a). The transportation of formulated nematodes requires extra care, as the IJs still need to maintain their viability and infectivity during application (Georgis, 1990). The temperature maintained during transportation therefore should always be kept at the point where survival and infectivity are not affected negatively.

\section{QUALITY ASSESSMENT}

Quality control during the production and formulation of EPNs is required for registration and commercialisation of the product (Ravensberg, 2011). For the successful control of insects, IJs have to locate and enter the host to release their bacterial symbionts to infect and kill the host successfully. Nematode quality assessment is aimed at measuring the ability of the nematodes to infect and kill the host, i.e. their infectivity/pathogenicity. This information reflects the ability of the IJs to kill the target insect in the field (Kagimu et al., 2017).

The foundation for maintaining high-quality formulated nematodes not only starts during formulation. High-quality nematodes are created during the production phase by ensuring the use of a suitable medium, bacteria and oxygen levels, and a complete production cycle, ending in the production of pure IJs. The focus of quality control should be the maintenance of pathogenicity during all the processes (production, formulation and storage) (Grewal, 2002a). The most popular method of measuring the infectivity of nematodes is that of undertaking insect bioassays. The 
bioassays include one-on-one bioassays, $\mathrm{LC}_{50}$, establishment efficacy and invasion rate assays (Navon et al., 2002). Controversy has emerged regarding bioassays that require the use of multiple nematodes against a single host due to host-parasite interactions, leading some to consider bioassays an inappropriate method of quality control (Hay \& Fenlon, 1995; Grewal et al., 1999).

Various factors must be considered when it comes to the quality of nematodes. For example, the longer the storage period, the more likely it is for the rate of infectivity to decrease, as the supply of stored energy on which the IJs depend becomes depleted (Patel et al., 1997b). An important factor to consider when assessing nematode quality is the production batch of nematodes, as they can differ in quality (Grewal, 2000a). The difference in the quality of nematode batches can be due to genetic drift in the inoculum used, as well as the age of the inoculum. During packaging, the estimation of expiry date is crucial to note, as the viability of the product might decrease over time (Grewal, 2000a; Kagimu et al., 2017). Such an estimation should assist the end user to know when they should expect the product efficacy to decrease. To counteract the problem, many companies formulate more than the stipulated amount that is indicated on the packet to compensate for any loss that might occur during storage and to ensure that the right amount of nematodes is available during application (Kagimu et al., 2017).

\section{APPLICATION TECHNOLOGY}

The most common method for the application of EPNs is by means of an aqueous suspension. The formulated nematodes are mixed with water and the WG-, wettable powder- and vermiculite-formulated nematodes are usually mixed directly into water. In the case of sponge formulations, the nematodes are simply squeezed out of the sponge. Alginate gel/beads cannot dissolve directly in water, but sodium citrate can be added to dissolve the gel (Georgis, 1990). Nematodes generally settle quickly in water suspensions, so the nematode suspension needs to be shaken and mixed constantly to ensure the uniform distribution of nematodes and the optimum oxygen supply during application (Georgis \& Kaya, 1998; Grewal \& Peters, 2005; Shapiro-Ilan et al., 2006). Applying or spraying the nematodes in the early morning is recommended, as the soil and air temperatures are cool enough not to desiccate them. During the day, the maximum temperature can negatively affect the persistence of the nematodes in the field (Shapiro-Ilan et al., 2012).

Almost all the agronomic equipment designed for the application of agrochemicals can be used to apply EPNs, including (but not limited to) mist blowers and both electrostatic and pressurised sprayers (Shapiro-Ilan et al., 2006). The end-point success of pesticides and biological control agents lies in using the most efficient and product-appropriate application method that will result in successful control strategies. Timing is very important during the application of EPNs, as their survival is affected considerably by both biotic and abiotic factors, including mostly desiccation by wind and UV radiation (Gaugler et al., 1997). Application in the early morning or in the afternoon is therefore recommended for the success of pest control programmes. Kaya (1990) suggests that the application of EPNs should be done immediately after the first sign of the pest population becomes evident.

\section{CONCLUSIONS}

There has been exponential growth in the use of EPNs as biocontrol agents for insect pests in recent years. However, the cost implications pertaining to the production, formulation and storage of EPNs play a very big role in establishing the high market value of EPNs. In some cases, the control of grapevine insect pests using EPNs may cost $10 \%$ to $60 \%$ more than chemical control. To accommodate the full extent of the available market, the production costs associated with the production of EPNs need to be reduced. Further research should investigate the use of cheaper diets and ways of shortening the length of production cycles.

Although significant progress has been made in the mass production of EPNs, the development of formulations with a prolonged shelf life is still a limiting factor in most countries, South Africa included. Recent studies have focused more on how to develop and improve high-quality EPN formulations - with longer storage periods than before - without affecting efficacy. Furthermore, microbial contamination is an important underlying factor affecting the development of improved formulations, with additional research being required to focus on suppressing the growth of microbial contaminants, as they degrade the formulated product. Fungal growth also competes with nematodes for oxygen, leading to a decreased survival percentage.

An important conclusion of this review is that, under optimum conditions, the inherent life expectancy of Steinernema in aqueous solutions is expected to be a maximum of six to eight months, and three to four months in the case of Heterorhabditis. Formulation using entrapment and gel slurries at room temperature can hardly be expected to produce longer life expectancy for an actively moving multicellular organism. Slight anhydrobiosis and low temperatures seem to be the most important factors that can be manipulated to obtain a longer shelf life. However, it was found that South African species cannot tolerate temperatures lower than $3^{\circ} \mathrm{C}$ to $6^{\circ} \mathrm{C}$ and perform best at temperatures of between $14^{\circ} \mathrm{C}$ and $25^{\circ} \mathrm{C}$, with intermediate results at room temperature. Low temperatures to slow down metabolic processes are therefore not suitable for South African nematodes. This makes the development of suitable formulations for South African EPNs more challenging, particularly for the control of above-ground pests.

The biotic and abiotic factors affecting the persistence of nematodes in the field require more focus than before, as they can also affect the effectiveness of EPNs, leading to the poor control of insects. Also, the laws and legislation governing the use of biological control agents should be revised as, in some cases, they have become stumbling blocks in the commercialisation of EPNs.

\section{ORCID NUMBERS}

A. Nxitywa https://orcid.org/0000-0002-3831-3534 A.P. Malan https://orcid.org/0000-0002-9257-0312 


\section{LITERATURE CITED}

Andalo, V., Moino, A., Maximiniamo, C., Campos V.P. \& Mendonca, L.A., 2011. Influence of temperature and duration of storage on the lipid reserves of entomopathogenic nematodes. Rev. Colomb. Entomol. 37, 203-209.

Ansari, M.A., Hussain, M.A. \& Moens, M., 2009. Formulation and application of entomopathogenic nematode-infected cadavers for control of Hoplia philanthus in turf grass. Pest. Manag. Sci. 65, 367-374. doi:10.1002/ ps.1699

Aquino-Bolaños, T., Morales-García, I. \& Martínez-Gutiérrez, G.A., 2019a Survival and effectiveness of entomopathogenic nematodes in oil emulsions against Scyphophorus acupunctatus Gyllenhal. Southwest Entomol. 44, 155-163. doi:10.3958/059.044.0117

Aquino-Bolaños, T., Ruiz-Vega, J., Hernández, Y.D.O. \& Castaneda, J.C.J. $2019 \mathrm{~b}$. Survival of entomopathogenic nematodes in oil emulsions and control effectiveness on adult engorged ticks (Acari: Ixodida). J. Nematol. 51, 1-10. doi:10.21307/jofnem-2019-001

Askary, T.H. \& Ahmad, M.J., 2017. Entomopathogenic nematodes: Mass production, formulation and application. In: Abd-Elgawad, M.M.M., Askary, T.H. \& Coupland, J. (eds). Biocontrol agents: Entomopathogenic and slug parasitic nematodes. CAB International, Wallingford. pp. $261-$ 286.

Banu, J.G., Cannayane, I. \& Meena, K.S., 2017. Entomopathogenic nematodes: General biology and behaviour. In: Abd-Elgawad, M.M.M., Askary, T.H. \& Coupland, J. (eds). Biocontrol agents: Entomopathogenic and slug parasitic nematodes. $\mathrm{CAB}$ International, Wallingford. pp. $63-87$.

Barrett, J., 1991. Anhydrobiotic nematodes. Agr. Z. Rev. 4, 161-176.

Batista, E.S.P. \& Auad, A.M., 2010. Application methods of entomopathogenic nematodes for control of Mahanarva spectabilis (Hemiptera: Cercopidae). Biocontr. Sci. Technol. 20, 1079-1085. doi:10.1 080/09583157.2010.515300

Bazardeh, M.E. \& Esmaiili, M., 2014. Sorption isotherm and state diagram in evaluating storage stability for sultana raisins. J. Stored Products Res. 59, 140-145. doi:10.1016/j.jspr.2014.07.001

Bečvář, S. \& Mráček, Z., 2000. Insect aggregations and entomopathogenic nematode occurrence. Nematology 2, 297-301. doi: $10.1163 / 156854100509169$

Bedding, R. \& Butler, K., 1994. Method for storage of insecticidal nematodes. World Patent No. WO 94/05150.

Bedding, R.A., 1984. Large scale production, storage and transport of the insect parasitic nematodes Neoaplectana spp. and Heterorhabditis spp. Ann. App. Biol. 104, 1170-120.

Bedding, R.A., 1988. Storage of insecticidal nematodes. World Patent No. WO 88/08668.

Capinera, J.L. \& Hibbard, B.E., 1987. Bait formulations of chemical and microbial insecticides for suppression of crop feeding grasshoppers. J. Agri. Entomol. 4, 337-344.

Chang, F.N. \& Gehret, M.J., 1992. Insecticide delivery system and attractant. US Patent No. 5, 141, 744.

Chen, S. \& Glazer, I., 2005. A novel method for long-term storage of the entomopathogenic nematode Steinernema feltiae at room temperature. Bio. Contr. 32, 104-110. doi:10.1016/j.biocontrol.2004.08.006

Cortés-Martínez, C.I., Lewis, E.E., Ruiz-Vega, J. \& Martínez-Gutiérrez, G.A., 2017. Mechanical production of pellets for the application of entomopathogenic nematodes: Effect of pre-acclimation of Steinernema glaseri on its survival time and infectivity against Phyllophaga vetula. Biocontr. Sci. Technol. 27(8), 940-951. doi:10.1080/09583157.2017.1366 423
Cortés-Martínez, C.I., Ruiz-Vega, J., Matadamas-Ortiz, P.T., Lewis, E.E., Aquino-Bolanos, T. \& Navarro-Antonio, J., 2016. Effect of moisture evaporation from diatomaceous earth pellets on storage stability of Steinernema glaseri. Biocontr. Sci. Technol. 26, 305-319. doi:10.1080/09 583157.2015.1104650

Costa, J.C.R., Dias, R.J.P. \& Morenz, M.J.F., 2007. Determining the adaptation potential of entomopathogenic nematode multiplication of Heterorhabditis baujardi and Steinernema carpocapsae (Rhabditida: Heterorhabditidae, Steinernematidae) in larvae of Alphitobius diaperinus (Coleoptera: Tenebrionidae) and Galleria mellonella (Lepidoptera: Pyralidae). Parasitol. Res. 102, 139-144. doi:10.1007/s00436-007-0747-9

Crowe, J.H. \& Crowe, L.M., 1992. Membrane integrity in anhydrobiotic organisms: Towards a mechanism for stabilizing dry cells. In: Somerso, G.N., Osmond, C.B. \& Bolis, C.L. (eds). Water and life. Springer-Verlag, Berlin. pp. $87-103$.

Del Valle, E.E., Dolinski, C., Barreto, E.L.S., Souza, R.M. \& Samuels, R.I 2008. Efficacy of Heterorhabditis baujardi LPP7 (Nematoda: Rhabditida) applied in Galleria mellonella (Lepidoptera: Pyralidae) insect cadavers to Conotrachelus psidii (Coleoptera: Curculionidae) larvae. Biocontr. Sci. Technol. 18, 33-41. doi:10.1080/09583150701721713

Dito, D.F., Shapiro-Ilan, D.I., Dunlap, C.A., Behle, R.W. \& Lewis, E.E., 2016. Enhanced biological control potential of the entomopathogenic nematode, Steinernema carpocapsae, applied with a protective gel formulation. Biocontrol Sci. Techn. 26, 835-848. doi:10.1080/09583157.2 016.1159659

Dlamini, T.M., Allsopp, E. \& Malan, A.P., 2020. Application of Steinernema yirgalemense to control Frankliniella occidentalis (Thysanoptera: Thripidae) on blueberries. Crop. Prot. 128, 105016. doi:10.1016/j.cropro.2019.105016

Dunn, M.D., Belur, P. \& Malan A.P., 2020a. In vitro liquid culture and optimization of Steinernema jeffreyense, using shake flasks. BioControl 65 , 223-233. doi:10.1007/s10526-019-09977-7

Dunn, M.D., Belur, P.D. \& Malan, A.P., 2020b. A review of the in vitro liquid mass culture of entomopathogenic nematodes. Biocontrol Sci. Technol. 31(1), 1-21. doi:10.1080/09583157.2020.1837072

Ehlers, R.-U., 2001. Mass production of entomopathogenic nematodes for plant protection. Appl. Microbiol. Biol. 56, 623-633. doi:10.1007/ s002530100711

Ehlers, R.-U., 2007. Entomopathogenic nematodes: From science to commercial use. In: Vincent, C., Goettel, M.S. \& Lazarovits, G. (eds). Biological control: A global perspective. Case studies from around the world CABI, Wallingford. pp. 136 - 151. doi:10.1079/9781845932657.0136

Ehlers, R.-U., Lunau, S., Krasomil-Osterfeld, K. \& Osterfeld, K.H., 1998. Liquid culture of the entomopathogenic nematode-bacterium-complex Heterorhabditis megidis-Photorhabdus luminescens. Biocontrol 43, 77-86. doi:10.1023/A:1009965922794

Ellenby, C., 1968. Desiccation survival in the plant parasitic nematodes, Heterodera rostochiensis Wollenweber and Ditylenchus dipsaci (Kuhn) Filipjev. Proc. Biol. Sci. 169, 203-213.

Ferreira, T., Addison, M.F. \& Malan, A.P., 2015. Development and population dynamics of Steinernema yirgalemense and growth characteristics of its associated Xenorhabdus symbiont in liquid culture. J. Helminthol. 90, 108112. doi:10.1017/S0022149X15000450

Ganguly, S., Kumar, A. \& Parmar, B.S., 2008. Nemagel - A formulation of the entomopathogenic nematode Steinernema thermophilum mitigating the shelf-life constraint of the tropics. Nematol. Mediter. 36, 125-130.

Gaugler, R., Wilson, M. \& Shearer, P., 1997. Field release and environmental fate of a transgenic entomopathogenic nematode. Biol. Control. 9, 75-80: doi:10.1006/bcon.1997.0538 
Georgis, R., 1990. Formulation and application technology. In: Gaugler, R. \& Kaya, H.K. (eds). Entomopathogenic nematodes in biological control. CRC Press, Boca Raton, FL. pp. 173 - 191

Georgis, R. \& Dunlop, D.B., 1994. Water dispersible granules: A novel formulation for nematode-based bioinsecticides. In: Proceedings of the British Crop Protection Conference 1994 - Pests and Diseases. British Crop Protection Council, Farnham. pp. $31-66$.

Georgis, R. \& Kaya, H.K., 1998. Formulation of entomopathogenic nematodes. In: Burges, H.D. (ed). Formulation of microbial biopesticides. Nematodes, and seed treatments. Dordrecht, Kluwer Academic Publishers. pp. 289 - 308. doi:10.1007/978-94-011-4926-6_9

Georgis, R., Dunlop, D.B. \& Grewal, P.S., 1995. Formulation of entomopathogenic nematodes. In: Hall, F.R. \& Barry, J.W. (eds). Biorational pest control agents: Formulation and delivery. American Chemical Society, Bethesda, MD. pp. $197-205$.

Glazer, I. \& Salame, L., 2000. Osmotic survival of the entomopathogenic nematode Steinernema carpocapsae. Biol. Control. 18, 251-257. doi:10.1006/bcon.2000.0814

Goud, S., Huger, P.S. \& Prabhuraj, A., 2010. Effect of temperature, population density and shelf life of EPN Heterorhabditis indica (RCR) in sodium alginate gel formulation. J. Biopestic. 3, 627-632.

Government Gazette of the Republic of South Africa, 1989. Agricultural Pest Amendment Act, 1989. Government Gazette Vol. 285, No. 11753, Government Printers, Pretoria. https://www.gov.za/sites/default/files/gcis document/201503/act-18-1989.pdf

Grewal, P.S., 1998. Formulations of entomopathogenic nematodes for storage and application. Japanese J. Nematol. 28, 68-74. doi:10.3725/ jjn1993.28.supplement_68

Grewal, P.S., 2002a. Formulation and application technology. In: Gaugler, R. (ed.). Entomopathogenic nematology. CABI Publishing, Wallingford, pp. 265-287. doi:10.1079/9780851995670.0265

Grewal, P.S., 2000b. Enhanced ambient storage stability of an entomopathogenic nematode through anhydrobiosis. Pest. Manage. Sci. 56, 401-406. https://doi.org/10.1002/(SICI)15264998(200005)56:5<401::AID-PS137>3.0.CO;2-4

Grewal, P.S., 2000c. Anhydrobiotic potential and long-term storage of entomopathogenic nematodes (Rhabditida: Steinernematidae). Inter. J. Parasitol. 30, 995-1000. doi:10.1016/S0020-7519(00)00080-1

Grewal, P. \& Georgis, R., 1998. Entomopathogenic nematodes. In: Hall, F.R. \& Menn, J.J. (eds). Methods in biotechnology, Vol. 5, Biopesticides: Use and delivery. Humana Press, Totowa, NJ. pp. 271 - 299.

Grewal, P.S. \& Jagdale, G.B., 2002. Enhanced trehalose accumulation and desiccation survival of entomopathogenic nematodes through cold preacclimation. Biocontr. Sci. Technol. 12, 533-545. doi:10.1080/0958315021000016207

Grewal, P.S. \& Peters, A., 2005. Formulation and quality. In: Grewal, P.S., Ehlers R.-U.\& Shapiro-Ilan, D.I.(eds). Nematodes as biocontrol agents. CABI Publishing, Wallingford. pp. 79 - 89. doi:10.1079/9780851990170.0079

Grewal P.S., Converse, V. \& Georgis R., 1999. Influence of production and bioassay methods on infectivity of two ambush foragers (Nematoda: Steinernematidae). J. Invertebr. Pathol. 73, 40-44.

Grzywacz, D., Moore, D. \& Rabindra, R.J., 2014. Mass production of entomopathogens in less industrialized countries. In: Morales-Ramos, J., Rojas, M.G. \& Shapiro-Ilan, D.I. (eds). Mass production of beneficial organisms. Elsevier, London. pp. 519 - 561. doi:10.1016/B978-0-12391453-8.00015-7

Guo, W., Yan, X. \& Han, R., 2017. Adapted formulations for entomopathogenic nematodes, Steinernema and Heterorhabditis spp. Nematology 19, 587-596. doi:10.1163/15685411-00003072
Han, R. \& Ehlers, R.-U., 2000. Pathogenicity, development, and reproduction of Heterorhabditis bacteriophora and Steinernema carpocapsae under axenic in vivo conditions. J. Invertebr. Pathol. 75, 55-58. doi:10.1006/ jipa. 1999.4900

Han, R. \& Ehlers, R., 2001. Effect of Photorhabdus luminescens phase variants on the in vivo and in vitro development and reproduction of the entomopathogenic nematodes Heterorhabditis bacteriophora and Steinernema carpocapsae. FEMS Microbiol. Ecol. 35, 239-247. doi:10.1111/j.1574-6941.2001.tb00809.x

Harington, J.S., 1953. Observation on the biology, the parasites and the taxonomic position of the maize beetle, Heteronychus sanctae-helenae Blanch. S. Afr. J. Sci. 50, 11-14.

Hatting, J.L. \& Malan, A.P., 2017. Status of entomopathogenic nematodes in integrated pest management strategies in South Africa. In: AbdElgawad, M.M.M., Askary, T.H. \& Coupland, J. (eds). Biocontrol agents: Entomopathogenic and slug parasitic nematodes. CABI, Wallington. pp. $409-428$.

Hatting, J.L., Moore, S.D. \& Malan, A.P., 2019. Microbial control of phytophagous invertebrate pests in South Africa: Current status and future. J. Invertebr. Pathol. 165, 54-66. doi:10.1016/j.jip.2018.02.004

Hay, D.B. \& Fenlon, J.S., 1995. A modified binomial model that describes the infection dynamics of the entomopathogenic nematode Steinernema feltiae (Steinernematidae; Nematoda). Parasitol. 111, 627-633. doi:10.1017/ S0031182000077118

Hazir, S., Kaya, H.K., Stock, S.P. \& Keskin, N., 2003. Entomopathogenic nematodes (Steinernematidae and Heterorhabditidae) for biological control of soil pests. Turkish J. Biol. 27, 181-202.

Heriberto, C.M., Jaime, R.V., Carlos, C.M. \& Jesusita, R.D., 2017. Formulation of entomopathogenic nematodes for crop pest control - A review. Plant Prot. Sci. 53, 15-24. doi:10.17221/35/2016-PPS

Hiltpold, I., Hibbard, B.E., French, B.W. \& Turlings, T.C.J., 2012. Capsules containing entomopathogenic nematodes as a Trojan horse approach to control the western corn rootworm. Plant and Soil 358, 11-25. doi:10.1007/ s11104-012-1253-0

Hussein, M.A. \& Abdel-Aty M.A., 2012. Formulation of two native entomopathogenic nematodes at room temperature. J. Biopest. 5, 23-27.

Kagimu, N., 2018. The development of a formulation for the commercialization of entomopathogenic nematodes. $\mathrm{PhD}$ dissertation, Stellenbosch University, Private Bag X1, 7602 Matieland (Stellenbosch), South Africa.

Kagimu, N. \& Malan, A.P., 2019. Formulation of South African entomopathogenic nematodes using alginate beads and diatomaceous earth. BioControl 64, 413-422. doi:10.1007/s10526-019-09945-1

Kagimu, N., Ferreira, T. \& Malan, A.P., 2017. The attributes of survival in the formulation of entomopathogenic nematodes utilised as insect biocontrol agents. Afr. Entomol. 25(2), 275-91. doi:10.4001/003.025.0275

Kaya, H.K., 1990. Soil ecology. In: Gaugler, R. \& Kaya H.K. (eds). Entomopathogenic nematodes in biological control. CRC Press, Boca Raton, FL. pp. $93-111$.

Kaya, H.K. \& Nelsen, C.E., 1985. Encapsulation of steinernematid and heterorhabditid nematodes with calcium alginate: A new approach for insect control and other applications. Environ. Entomol. 14, 572-574: https://doi. org/10.1093/ee/14.5.572

Kim, J., Jaffuel, G. \& Turlings, T.C.J., 2015. Enhanced alginate capsule properties as a formulation of entomopathogenic nematodes. BioControl 60, 527-535. doi:10.1007/s10526-014-9638-z

Leite, L.G., Shapiro-Ilan, D.I. \& Hazir, S., 2018. Survival of Steinernema feltiae in different formulation substrates: Improved longevity in a mixture of gel and vermiculite. Biol. Control. 126, 192-197. doi:10.1016/j. biocontrol.2018.05.013 
Le Vieux, P.D. \& Malan, A.P., 2013. The potential use of entomopathogenic nematodes to control Planococcus ficus (Signoret) (Hemiptera: Pseudococcidae). S. Afr. J. Enol. 34(2), 296-306.

Lewis, E.E. \& Perez, E.E., 2004. Formulation and storage of entomopathogenic nematodes. Int. J. Nematol. 14, 30-34.

Ley, P. \& Mundo-Campos, M., 2004. Cultivation of nematodes. In: Chen, Z.X., Chen S.Y. \& Dickson, D.W. (eds). Nematology advances and perspectives. CABI Publishing, Wallingford. pp. $541-561$.

Lu, D., Macchietto, M., Chang, D., Barros, M.M., Baldwin, J., Mortazavi, A. \& Dillman, A.R., 2017. Activated entomopathogenic nematode infective juveniles release lethal venom proteins. PLoS Pathog. 13(4), e1006302. doi:10.1371/journal.ppat.1006302

Malan, A.P. \& Ferreira, T., 2017. Entomopathogenic nematodes. In: Fourie, H., Spaull, V.W., Jones, R.K., Daneel, M.S. \& De Waele, D. (eds). Nematology in South Africa: A view from the 21st century. Springer International, Cham. pp. $459-480$.

Malan, A.P. \& Hatting, J.L., 2015. Entomopathogenic nematode exploitation: Case studies in laboratory and field applications from South Africa. In: Campos-Herrera, R. (ed.). Nematode pathogenesis of insects and other pests. Springer, Cham. pp. 477 - 508. doi:10.1007/978-3-319-18266720

Malan, A.P., Knoetze, R. \& Moore, S.D., 2011. Isolation and identification of entomopathogenic nematodes from citrus orchards in South Africa and their biocontrol potential against false codling moth. J. Invertebr. Pathol. 108, 115-125. doi:10.1016/j.jip.2011.07.006

Monteiro, D.C.M., Matos, D.R., Araújo, L.X., Campos, R., Bittencourt, V.R.E.P., Dolinski, C., Furlong, J. \& Prata, D.M.C., 2014. Entomopathogenic nematodes in insect cadaver formulations for the control of Rhipicephalus microplus (Acari: Ixodidae). Vet. Parasitol. 203, 310-317. doi:10.1016/j. vetpar.2014.04.003

Navon, A., Nagalakshmi, V.K., Levski, S., Salame, L. \& Glazer, I., 2002. Effectiveness of entomopathogenic nematodes in an alginate gel formulation against lepidopterous pests. Biocontrol Sci. Technol. 12, 737746. doi:10.1080/0958315021000039914

Nimkingrat, P., Uhlmann, F., Strauch, O. \& Ehlers, R.-U., 2013. Desiccation tolerance of dauers of entomopathogenic nematodes of the genus Steinernema. Nematology 15, 451-458. doi:10.1163/15685411-00002692

Noosidum, A., Satwong, P., Chandrapatya, A. \& Lewis E.E., 2016. Efficacy of Steinernema spp. plus anti-desiccants to control two serious foliage pests of vegetable crops, Spodoptera litura F. and Plutella xylostella L. Biol. Control. 97, 48-56. doi:10.1016/j.biocontrol.2016.03.004

Patel, A.V. \& Vorlop, K.-D., 1994. Entrapment of biological control agents applied to entomopathogenic nematodes. Biotechnol. Tech. 8, 569-574.

Patel, M.N. \& Wright, D.J., 1997a. Glycogen: Its importance in the infectivity of aged juveniles of Steinernema carpocapsae. Parasitol. 114, 591-596. doi:10.1017/S0031182097008780

Patel, M.N. \& Wright D.J., 1997b. Fatty acid composition of neutral lipid energy reserves in infective juveniles of entomopathogenic nematodes. Comp. Biochem. Phys. A. 118(2), 341-348. doi:10.1016/S03050491(97)00057-6

Patel, M.N. \& Wright, D.J., 1997c. Phospholipid fatty acid composition in steinernematid entomopathogenic nematodes. Comp. Biochem. Phys. A. $118,649-657$.

Patel, M.N., Perry, R.N. \& Wright D.J., 1997a. Desiccation survival and water contents of entomopathogenic nematodes, Steinernema spp. (Rhabditida: Steinernematidae). Int. J. Parasitol. 27, 61-70, doi:10.1016/ S0020-7519(96)00154-3
Patel, M.N., Stolinski, M. \& Wright, D.J., 1997b. Neutral lipids and the assessment of infectivity of entomopathogenic nematodes: observations on four Steinernema species. Parasitol. 114, 489-496. doi:10.1017/ S0031182096008748

Perry, R.N., Ehlers, R.-U. \& Glazer I., 2012. A realistic appraisal of methods to enhance desiccation tolerance of entomopathogenic nematodes. J. Nematol. 44, 185-190.

Platt, T., Stokwe, N.F. \& Malan, A.P., 2018. Foliar application of Steinernema yirgalemense to control Planococcus ficus: Assessing adjuvants to improve efficacy. S. Afr. J. Enol. Vitic. 40, 13-19. doi:10.21548/40-1-2920

Platt, T., Stokwe, N.F. \& Malan A.P., 2020. Review of the potential use of entomopathogenic nematodes to control above-ground insect pests in South Africa. S. Afr. J. Enol. Vitic. 43, 1-16. doi:10.21548/41-1-2424

Poinar, G.O., 1990. Taxonomy and biology of Steinernematidae and Heterorhabditidae. In: Gaugler, R. \& Kaya, H.K. (eds). Entomopathogenic nematodes in biological control. CRC Press, Boca Raton, FL. pp. $23-61$.

Portman, S.L., Krishnankutty, S.M. \& Reddy, G.V., 2016. Entomopathogenic nematodes combined with adjuvants presents a new potential biological control method for managing the wheat stem sawfly, Cephus cinctus (Hymenoptera: Cephidae). PloS One, 11(12), e0169022. doi:10.1371/ journal.pone.0169022

Ramakuwela, T., Hatting, J., Laing, M.D., Hazir, S. \& Thiebaut, N., 2015. Effect of storage temperature and duration on survival and infectivity of Steinernema innovationi (Rhabditida: Steinernematidae). J. Nematol. 47, 332-336. doi:10.1016/j.jip.2008.02.013

Ravensberg, W., 2011. A roadmap to the successful development and commercialization of microbial pest control products for control of arthropods. Springer, New York.

Ruiz-Vega, J., Cortés-Martínez, C.I. \& García-Gutiérrez, C., 2018. Survival and infectivity of entomopathogenic nematodes formulated in sodium alginate beads. J. Nematol. 50, 273-280. doi:10.21307/jofnem-2018-037

San-Blas, E., 2013. Progress on entomopathogenic nematology research: A bibliometric study of the last three decades: 1980-2010. Biol. Control. 66, 102-124. doi:10.1016/j.biocontrol.2013.04.002

Selvan, S., Gaugler, R. \& Grewal P.S., 1993. Water-content and fatty-acid composition of infective juvenile entomopathogenic nematodes during storage. J. Parasitol. 79, 510-516. doi:10.2307/3283375

Shapiro-Ilan, D.I. \& Gaugler, R., 2002. Production technology for entomopathogenic nematodes and their bacterial symbionts. J. Ind. Microbiol. Biol. 28, 137-146. doi:10.1038/sj/jim/7000230

Shapiro-Ilan, D.I., Gaugler, R., Tedders, W.L., Brown, I. \& Lewis, E.E., 2002. Optimization of inoculation for in vivo production of entomopathogenic nematodes. J. Nematol. 34, 343-350.

Shapiro-Ilan, D.I., Gouge, D.H., Piggott, S.J. \& Fife, J.P., 2006. Application technology and environmental considerations for use of entomopathogenic nematodes in biological control. Biol. Control. 38, 124-133. doi:10.1016/j. biocontrol.2005.09.005

Shapiro-Ilan, D.I., Han, R. \& Dolinksi, C., 2012. Entomopathogenic nematode production and application technology. J. Nematol. 44, 206-217.

Shapiro-Ilan, D.I., Lewis, E.E., Behle, R.W. \& McGuire, M.R., 2001. Formulation of entomopathogenic nematode-infected cadavers. J. Invertebr. Pathol. 78, 17-23. doi:10.1006/jipa.2001.5030

Shapiro-Ilan, D.I., Morales-Ramos, J.A., Rojas, M.G. \& Tedders, W.L., 2010. Effects of a novel entomopathogenic nematode-infected host formulation on cadaver integrity, nematode yield, and suppression of Diaprepes abbreviates and Aethina tumida. J. Invertebr. Pathol. 103, $103-$ 108. doi:10.1016/j.jip.2009.11.006 
Silver, S.C., 1999. Granular formulation of biological entities with improved storage stability. US Patent 5, 965, 149.

Silver, S.C., Dunlop, D.B. \& Grove, D.I., 1995. Granular formulations of biological entities with improved storage stability. World Patent No. WO $95 / 0577$.

Spaull, V.W., 1988. A preliminary evaluation of entomogenous nematodes to control the African sugarcane stalk borer Eldana saccharina (Lepidoptera: Pyralidae). Proceedings of the South African Sugar Technologists' Association, 62, 120-123.

Steyn, L.A.I., Addison, P. \& Malan, A.P., 2019a. Potential of South African entomopathogenic nematodes to control the leaf miner, Holocacista capensis (Lepidoptera: Heliozelidae). S. Afr. J. Enol. Vitic. 40, 301-307. doi:10.21548/40-2-3420

Steyn, V.M., Malan, A.P. \& Addison, P., 2019b. Control of false codling moth, Thaumatotibia leucotreta (Lepidoptera: Tortricidae), using in vitrocultured Steinernema jeffreyense and S. yirgalemense. Biol. Control 104052. https://doi.org/10.1016/j.biocontrol.2019.104052

Stock, S.P., 2015. Diversity, biology and evolutionary relationships. In: Campos-Herrera, R. (ed.). Nematode pathogenesis of insects and other pests: Ecology and applied technologies for sustainable plant and crop protection. Springer International, Cham. pp. $3-27$.

Strauch, O., Niemann, I., Neumann, A., Schmidt, A.J., Peters, A. \& Ehlers, R.U., 2000. Storage and formulation of the entomopathogenic nematodes Heterorhabditis indica and H. bacteriophora. BioControl 45, 483-500. doi:10.1023/a:1026528727365
Van Zyl, C. \& Malan, A.P., 2015. Cost-effective culturing of Galleria mellonella and Tenebrio molitor and nematode production in various hosts. Afr. Entomol. 23, 361-375. doi:10.4001/003.023.0232

Vemmer, M. \& Patel, A.V., 2013. Review of encapsulation methods suitable for microbial biological control agents. Biol. Control. 67, 380-389. doi:10.1016/j.biocontrol.2013.09.003

Vos, J.G., Dybing, E., Greim, H.A., Ladefoged, O., Lambre, C., Tarazona, J.V., Brandt. I. \& Vethaak A.D., 2000. Health effects of endocrine-disrupting chemicals on wildlife, with special reference to the European situation. Crit. Rev. Toxicol. 30, 71-133. doi:10.1080/10408440091159176

Westerman, P.R., 1992. The influence of time of storage on performance of the insect parasitic nematode, Heterorhabditis sp. Fun. Appl. Nematol. $15,407-412$.

Wharton, D.A., 1986. A functional biology of nematodes. Croom Helm, London.

Wharton, D.A., 2002. Life at the limits: Organisms in extreme environments. Cambridge University Press, Cambridge.

Womersley, C.Z., 1990. Dehydration survival and anhydrobiotic potential. In: Gaugler, R. \& Kaya, H.K. (eds). Entomopathogenic nematodes in biological control. CRC Press, Boca Raton, FA. pp. 117 - 137.

Womersley, C.Z., Higa, L.M. \& Wharton, D.H., 1998. Survival biology. In: Perry, R.N. \& Wright, D.J. (eds). The physiology and biochemistry of freeliving and plant-parasitic nematodes. CAB International, Wallingford. pp. $271-302$. 